Ciência e Natura, Santa Maria v.38 n.1, 2016, Jan.- Abr. p. 484 - 493

Revista do Centro de Ciências Naturais e Exatas - UFSM

ISSN impressa: 0100-8307 ISSN on-line: 2179-460X

\title{
Animais do cerrado: indo além da sala de aula
}

\author{
Animals of cerrado: going beyond the classroom
}

\author{
Renata Cardoso de Sá Ribeiro Razuck ${ }^{1}$, Delano Moody Simões da Silva ${ }^{2}$ \\ ${ }^{1}$ Doutor em Educação, Divisão de Ensino de Química, Instituto de Química, \\ Universidade de Brasília, Brasília, Brasil \\ renatarazuck@unb.br \\ ${ }^{2}$ Doutor em Ecologia, Área de Educação, Faculdade UnB Planaltina, \\ Universidade de Brasília, Brasília, Brasil \\ delanom@unb.br
}

\begin{abstract}
Resumo
uscando valorizar a atividade experimental como estratégia didática fundamental no processo de ensino-aprendizagem de Ciências :alizamos uma atividade experimental destinada a alunos do sétimo ano do Ensino Fundamental organizada por Professores Coordenadores o Programa Institucional de Bolsas de Iniciação à Docência (Pibid) em conjunto com os alunos bolsistas e Professores Supervisores da ecretaria de Educação do Distrito Federal. Tal atividade iniciou-se com uma saída de campo para a observação do bioma local (Cerrado). Em 'guida os alunos foram conduzidos ao Laboratório e divididos em grupos para manusear animais vertebrados e invertebrados típicos do 'errado. Após o manuseio dos exemplares de animais, os alunos apresentaram os grupos de animais para a turma, sintetizando as iracterísticas abordadas (alimentação, respiração e reprodução). A atividade proporcionou aos alunos a experiência de estudar sobre as asses de animais que verdadeiramente compõe a fauna presente em seu cotidiano e também colaborou no processo de se perceberem como ıdivíduos participantes desse complexo e importante meio, além de contribuir para uma visão do bioma cerrado mais completa. Atividades mo a aqui descrita favorece tanto a aprendizagem dos alunos quanto à formação inicial e continuada de professores.
\end{abstract}

'alavras-chave: Atividade experimental. Bioma Cerrado. Pibid, Formação de Professores. Ciências Naturais.

\begin{abstract}
eeking to enhance the experimental activity as a key teaching strategy in the teaching-learning process of Sciences conducted an sperimental activity aimed at students of the seventh grade of elementary school teachers organized by the "Programa Institucional de Bolsa - Iniciação à Docência" (Pibid) together with the scholarship students and Supervisors Teachers Education Department of the Federal istrict. This activity began with a field trip to observe the local biome (Cerrado). Then the students were carried to the laboratory and ivided into groups to handle vertebrates and invertebrates typical of the Cerrado. After handling the specimens of animals, students resented a groups to the class, summarizing the characteristics addressed (feeding, respiration and reproduction). The activity gave udents the experience of studying about the classes of animals that truly make up the fauna present in their daily lives and see themselves ; participants in this complex and important means individuals, and contribute to a vision of the Cerrado biome more compatible . ctivities as described here favors both student learning for the initial and continuing teacher education.
\end{abstract}

eywords: Experimental Activit. Cerra., Pibid. Teacher Education. Natural Sciences. 


\section{Introdução}

Podemos dizer que a Ciência tem como característica essencial o seu caráter experimental (SILVA, MACHADO E TUNES, 2010). Atualmente, segundo os Parâmetros Curriculares Nacionais - PCN (BRASIL, 1998), as Orientações Curriculares Nacionais - OCN (BRASIL, 2006), as Orientações Educacionais Complementares aos Parâmetros Curriculares Nacionais - PCN + (BRASIL, 2002) e as Diretrizes Curriculares Nacionais para a Educação Básica DCN (BRASIL, 2013) a experimentação é recomendada como forma de valorizar as interrelações entre teoria e prática, saberes cotidiano e a formação de valores éticos e morais. Porém, como a experimentação não é um componente curricular obrigatório nas escolas, muitas vezes acaba sendo apresentada como um apêndice ao ensino, normalmente centrado no desenvolvimento de conteúdos de Ciências, de forma reducionista, com o intuito de ilustrar ou comprovar a teoria (FRAGAL et al., 2011).

Autores como Silva e Zanon (2000) afirmam que a simples existência de aulas experimentais não assegura, por si só, a promoção de aprendizagens. Uma abordagem tradicional (na qual o professor "ensina" e os alunos "aprendem") pode vir a comprometer a qualidade do ensino, assim como perpassar uma concepção inadequada do que é Ciência. A visão indutivista e empirista da realidade que "está aí fora" para ser descoberta remete a um dogmatismo científico, considerado como a única forma verdadeira e definitiva de explicação para qualquer questão (Hodson, 1994; Silva e Zanon, 2000; Silva e Núñez, 2002; Galiazzi e Gonçalves, 2004).

Conforme Lôbo (2012), é praticamente consenso que a experimentação é um importante recurso didático para o ensino de Ciências. Nesse mesmo enfoque, Giordan (1999) afirma que é de conhecimento dos professores que a experimentação desperta o interesse entre alunos de diversos níveis de escolarização e pode estimular o aprendizado. $\mathrm{O}$ autor relata que os alunos costumam atribuir à experimentação um caráter motivador e lúdico, o que é questionado por Hodson (1994). Esse último afirma que nem sempre as atividades experimentais são motivadoras. Hodson (1984), inclusive, comenta que alguns alunos não vêem a experimentação como algo atrativo e significante para seu aprendizado, já que em atividades experimentais é frequente a preocupação em executar roteiros de forma reprodutiva e não investigativa, o que acaba por contribuir para uma visão errônea de que a Ciência é sempre correta e inquestionável (FRAGAL et al., 2011).

Segundo Santos (2006), as aulas experimentais devem primar pelo desenvolvimento da criticidade em relação aos resultados obtidos nas práticas, os quais não precisam ser, obrigatoriamente, os esperados. Deve-se buscar a discussão das ideias de modo a favorecer o desenvolvimento da capacidade de observação, argumentação, de conexão entre os fenômenos estudados e os dados observados.

Um aspecto importante a ser ressaltado nas atividades experimentais é que estas devem apresentar um caráter investigativo. Hodson (1994) afirma que muitos alunos não conseguem estabelecer relações entre o material concreto que manipula e os dados obtidos. Realizam o experimento e não sabem o que fazer com os dados, como analisar e interpretar seus resultados. As atividades experimentais propiciam a obtenção de dados que ao serem analisados podem conduzir à conclusões pertinentes sobre uma realidade. Conforme Hodson (1994), Carvalho et al (1999), Silva, Machado e Tunes (2010), Lôbo (2012), dentre outros, deve-se evitar a mera comprovação de fenômenos, já que não cabe à experimentação a verificação da teoria, tendo em vista que as contribuições teóricas são provenientes das observações práticas. Deve-se priorizar o caráter investigativo, cabendo a experimentação o papel de estimular a inquietação e o levantamento de hipóteses, e não a mera comprovação de uma teoria.Hodson (1994) defende que o ensino experimental deve envolver menos prática e mais reflexão.

Nesse sentido, ao enfocarmos a estratégia da experimentação, adotamos a concepção de Silva, Machado e Tunes (2010) sobre a definição de atividades experimentais. Segundo essa concepção, atividades experimentais são aquelas realizadas não somente em laboratórios de 
ensino, mas em diversos locais, como a sala de aula, o jardim da escola, uma horta, uma saída de campo e etc. e que possuem como eixos norteadores a não dissociação dos processos de ensinar e aprender; a indissociação da teoria com o experimento; a escolha de contextos interdisciplinares e com enfoque ambiental (SILVA, MACHADO E TUNES, 2010). Nessa perspectiva, o principal objetivo das atividades experimentais é "contribuir para o estabelecimento de relações entre os níveis teórico-conceitual e fenomenológico" (LOBO, 2012, p. 432), dando subsídios à construção conceitual. Tais atividades têm a finalidade de favorecer, a partir de sua estrutura dinâmica, "a formação e o desenvolvimento do pensamento analítico teoricamente orientado" (SILVA, MACHADO E TUNES, 2010, p. 240), o que é principalmente propiciado a partir da fragmentação da observação fenomenológica seguida pela reflexão e recombinação dos fragmentos observados para o alcance de uma compreensão mais global, sempre guiada teoricamente.

Nesse contexto, torna-se necessário valorizar a atividade experimental como estratégia didática fundamental no processo de ensinoaprendizagem de Ciências. Com esse enfoque passaremos a relatar a realização de uma atividade experimental destinada a alunos do sétimo ano do Ensino Fundamental e organizada por Professores Coordenadores do Programa Institucional de Bolsas de Iniciação à Docência (Pibid) em conjunto com os alunos bolsistas e Professores Supervisores da Secretaria de Educação do Distrito Federal.

\section{A atuação do Pibid de Ciências Naturais}

Objetivando diminuir ainda mais o distanciamento entre a realidade e a formação de professores, a Coordenação de Aperfeiçoamento de Pessoal de Nível Superior (Capes) criou o Programa Institucional de Bolsas de Iniciação à Docência (Pibid), com o objetivo de fomentar a formação inicial de profissionais do magistério, seguindo as diretrizes do Plano de Metas Compromisso Todos pela Educação, estipuladas pelo Decreto no 6.094, de 24 de abril de 2007, e aos princípios da Política Nacional de Formação de Profissionais do Magistério da Educação
Básica, instituída pelo Decreto no 6.755, de 29 de janeiro de 2009. Nesse programa licenciandos são selecionados para atuar nas escolas juntamente com professores supervisores (Educação Básica) e professores coordenadores (IES).

Nesta perspectiva o Pibid tem como objetivo principal a formação de licenciados para atuar com excelência na Educação Básica. Com certeza, este processo formativo propiciado pelo Pibid também favorece a formação continuada dos professores envolvidos e a aproximação Universidade - Escola, tão almejada por ambas as esferas educacionais.

Os projetos desenvolvidos no Pibid de Ciências Naturais da Faculdade UnB Planaltina (FUP) privilegiam a integração entre atividades de extensão, ensino e pesquisa. As atividades desenvolvidas no Pibid de Ciências Naturais baseiam-se principalmente na observação e reflexão sobre a realidade escolar, seguida pela ação no meio escolar e reflexão sobre essa ação.

A observação sobre a realidade escolar é iniciada pela inserção dos licenciandos bolsistas nas salas de aula e a reflexão sobre esta realidade é direcionada por referenciais teóricos que iluminam o olhar e a percepção, favorecendo a interpretação desta realidade e a aproximação Universidade - Escola a partir das demandas apresentadas pela instituição escolar. Em seguida, o grupo Pibid é desafiado a propor estratégias que atendam as demandas e necessidades da escola. Essa busca por alternativas é propiciadora de importantes momentos de aprendizado para o grupo. Ao aplicar tais estratégias na instituição escolar, o grupo Pibid é instigado a novamente refletir sobre esta atuação, configurando este um importante momento de avaliação e crescimento quanto à praxi pedagógica. Esse processo de atuação tem favorecido não só a formação do futuro professor, mas também tem propiciado importantes momentos de incentivo à reflexão do professor supervisor quanto a sua práxi e oportunizado a aproximação da formação pela pesquisa no espaço escolar.

No curso de Licenciatura em Ciências Naturais da Universidade de Brasília temos uma equipe composta por 10 bolsistas licenciandos que são acompanhados por 2 professores supervisores atuantes na Educação Básica e dois coordenadores pesquisadores da Universidade. 
Os professores supervisores atuam na Secretaria de Educação do Distrito Federal (SEDF) em sistema de dedicação exclusiva com jornada de trabalho de $40 \mathrm{~h}$ semanais. Tais professores supervisores estão lotados com regência de classe em Ciências em duas diferentes escolas que atendem aos anos finais do Ensino Fundamental. Cada professor supervisor é acompanhado por cinco 5 licenciandos bolsistas. Cada licenciando bolsista cumpre uma carga horária de $15 \mathrm{~h}$ semanais na escola, período em que não apenas tem a oportunidade de acompanhar as aulas, mas também momentos de planejamento, reuniões e etc.

Ao longo do segundo semestre de 2011, diversas atividades foram realizadas pelo grupo Pibid de Ciências Naturais, sendo uma delas selecionada para ilustrar este artigo: Cerrado: características e diversidade.

\section{A abordagem do tema Cerrado}

A partir da observação da prática pedagógica junto a turmas de sétimo ano do Ensino Fundamental, identificou-se que o estudo sobre o reino dos animais se resumia em apresentar as classes (tanto de invertebrados quanto de vertebrados) destacando suas características principais. Tais conteúdos não eram apresentados de forma conexa a realidade dos alunos e as aulas costumavam serem expositivas, assim entendidas como aquelas em que o professor expõe o conteúdo de forma semelhante ao livro didático e os alunos permanecem passivos (KRASILCHIK, 2004).

Para Krasilchik (2004), a passividade dos alunos durante as aulas expositivas é um obstáculo ao processo de ensino aprendizado. Segundo a autora, a retenção de informações nas aulas expositivas é pequena, sendo a diminuição da atenção dos alunos ao longo da aula um dos fatores que podem explicar este fato. Krasilchik (2004) aponta que para obter e manter a atenção dos alunos é necessário instigá-los intelectualmente e diversificar a prática pedagógica.

Documentos oficiais do Ministério da Educação e Cultura, tais como os PCN (1998), os $\mathrm{PCN}+$ (2002) e as Orientações Curriculares Nacionais (2006) também sugerem o uso da experimentação com foco interdisciplinar e abordagem atrelada ao cotidiano do aluno como uma estratégia para o processo de ensino aprendizado. Além disso, os próprios PCN indicam que o estudo da diversidade dos seres vivos não deve ser restrito a observação de imagens em livros.

Com o intuito de realizar uma atividade experimental que propiciasse o desenvolvimento do pensamento analítico e assim favorecesse o avanço no processo de aprendizagem, propôs-se para os alunos do sétimo ano de duas escolas públicas do Distrito Federal na qual o Pibid tem um grupo de cinco alunos bolsistas e um professor supervisor em cada escola, uma atividade experimental que almejava trabalhar diversos grupos animais de forma contextualizada.

Tal atividade iniciou-se com uma saída de campo em um parque ecológico próximo ao campus da Universidade de Brasília em Planaltina - DF. Neste parque foi possível observar o bioma local - Cerrado - enfocando sua flora, fauna, situação ambiental e social. A saída de campo foi guiada por um professor pesquisador da Universidade de Brasília em conjunto com o professor supervisor e os alunos bolsistas. Essa atividade de saída de campo foi explorada em um artigo específico (SILVA; RAZUCK, 2012).

Após a referida saída de campo, os alunos foram conduzidos ao Laboratório de Apoio e Pesquisa em Ensino de Ciências (LAPEC) e foram organizados em oito grupos (cada escola), com atendimento de quatro grupos por vez. Com o intuito de identificar a percepção dos alunos sobre algumas características animais, inicialmente solicitamos que anotassem, em grupos, como caracterizavam a alimentação, respiração e reprodução dos peixes, anfíbios, répteis, aves e mamíferos. As anotações dos alunos foram recolhidas e serão apresentadas nos resultados.

Logo em seguida, os alunos tiveram a oportunidade de, em grupo, manusear animais vertebrados e invertebrados típicos do Cerrado a fim de melhor observar suas características e debater sobre seus hábitos. No atendimento direcionado a cada escola foi possível organizálos em oito grupos para as atividades no LAPEC. Nessa oportunidade, os alunos utilizaram luvas descartáveis e manusearam amostras reais de animais conservados em álcool $70 \%$, conforme o Quadro 01: 


\begin{tabular}{|l|c|}
\hline Grupos & Representantes \\
\hline Crustáceos & Tatu bola \\
\hline Insetos & $\begin{array}{c}\text { Borboletas, mariposas, besouros, grilos, } \\
\text { barbeiros, abelhas }\end{array}$ \\
\hline Aracnídeos & Aranhas e carrapatos \\
\hline Quilópodes & Lacraia e centopeia \\
\hline Anfíbios & Sapos, pererecas, rãs e salamandra \\
\hline Répteis & Lagartos, calangos e cobras diversas \\
\hline Mamíferos & Gambá, rato e modelos humanos \\
\hline Aves & Corujas \\
\hline
\end{tabular}

Quadro 1: Relação de animais trabalhas na atividade experimental seguindo a organização tradicionalmente trabalhada na escola (e não as normas atuais de classificação biológica).

A atividade foi guiada por um professor pesquisador da Universidade de Brasília acompanhado pelo professor supervisor e por alunos bolsistas do Pibid. Ao longo da atividade os alunos foram incentivados a debater sobre características referentes à alimentação, reprodução e respiração dos referidos animais. Em seguida, os alunos foram conduzidos a refletirem a cerca do processo evolutivo de tais animais e foram desafiados a tentar estabelecer correlações entre suas características alimentares, respiratórias, reprodutivas e evolutivas. Então foi solicitado que os alunos anotassem uma possível sequência evolutiva apresentando explicações que justificassem a sequência elaborada.

Vale destacar que durante a atividade experimental foi principalmente enfocada as características dos grupos animais, sem muita ênfase a nomenclatura referente a cada grupo ou a questões mais específicas da sistemática e taxonomia. A todo o momento a forma de abordagem utilizada pelos professores e monitores visava instigar os alunos a refletirem sobre as características dos grupos animais e a correlação destas com a teoria evolutiva, ainda de uma forma inicial, considerando que os alunos atendidos se encontravam nos anos finais do Ensino Fundamental.

\section{Resultados}

Ao longo da atividade observamos que os alunos ficaram muito empolgados com a visita ao Parque Sucupira e a Universidade e demonstraram especial interesse quanto as atividades desenvolvidas no LAPEC.

Após algumas explicações iniciais sobre a organização do espaço físico e da atividade proposta, organizamos os alunos em quatro grupos e solicitamos que discutissem e fizessem anotações sobre as características dos peixes, anfíbios, répteis, mamíferos e aves quanto à alimentação, respiração e reprodução. As anotações dos alunos foram recolhidas ao final da atividade. Ao longo da conversação com os grupos foi evidente que haviam muitas dúvidas, como podemos ver no quadro a seguir em que analisamos e classificamos as respostas dos alunos como aceitáveis ou inaceitáveis:

\begin{tabular}{|c|c|c|c|}
\hline Grupo & & Aceitável & $\begin{array}{c}\text { Não } \\
\text { Aceitável }\end{array}$ \\
\hline \multirow{3}{*}{ Peixes } & Alimentação & 14 & 2 \\
\hline & Respiração & 13 & 3 \\
\hline & Reprodução & 8 & 8 \\
\hline \multirow{3}{*}{ Anfíbios } & Alimentação & 16 & 0 \\
\hline & Respiração & 7 & 9 \\
\hline & Reprodução & 10 & 6 \\
\hline \multirow{3}{*}{ Répteis } & Alimentação & 14 & 2 \\
\hline & Respiração & 8 & 8 \\
\hline & Reprodução & 10 & 6 \\
\hline \multirow{3}{*}{ Mamíferos } & Alimentação & 2 & 14 \\
\hline & Respiração & 13 & 3 \\
\hline & Reprodução & 15 & 1 \\
\hline \multirow{3}{*}{ Aves } & Alimentação & 12 & 4 \\
\hline & Respiração & 14 & 2 \\
\hline & Reprodução & 15 & 1 \\
\hline
\end{tabular}

Quadro 2: Classificação das respostas dos alunos como aceitáveis e não aceitáveis. 
Para um maior esclarecimento de como classificamos as anotações dos alunos como aceitáveis ou inaceitáveis traremos alguns exemplos no Quadro 3 para a discussão.

\begin{tabular}{|c|c|}
\hline Grupo & Respostas destacadas \\
\hline Peixes & $\begin{array}{l}\text { Reprodução assexuada. } \\
\text { Reprodução assexuada externa. } \\
\text { Assexuada com poucos gametas. } \\
\text { Respiração pulmonar. Alimentação de água. }\end{array}$ \\
\hline Anfíbios & $\begin{array}{l}\text { A reprodução é por ovinhos, assexuada. Ele } \\
\text { respira pela pele, que tem um monte de furinho, an } \\
\text { ele respira. } \\
\text { Anfíbios respiram pelo pulmão e pela narina. } \\
\text { A respiração dos anfíbios: pelas narinas. } \\
\text { A respiração dos anfibios é pulmonar, } \\
\text { branquial e pela pele. } \\
\text { Respiração: branquial e cutânea. } \\
\text { Respiração: pulmonar, por meio de } \\
\text { brânquias. }\end{array}$ \\
\hline Répteis & $\begin{array}{l}\text { Respiração: eles usam o pulmão e as } \\
\text { brânquias. Reprodução: externa-assexuada. } \\
\text { Répteis (respiração): brânquias e pulmões. } \\
\text { Répteis (reprodução): assexuada e externa. } \\
\text { Répteis: pulmões e narinas. } \\
\text { Respiração dos répteis: narina. Reprodução: } \\
\text { asexuada } \\
\text { Respiração dos répteis: pulmonar e alguns } \\
\text { pela pele, dependendo do animal. } \\
\text { Respiração: por brânquias e pulmão. } \\
\text { Répteis respiração:cutânea e pulmonar. }\end{array}$ \\
\hline Mamíferos & $\begin{array}{l}\text { Mamíferos - alimentação: leite materno, } \\
\text { depois de crescidos são carnívoros e herbívoros. } \\
\text { Nenhum animal produz seu próprio } \\
\text { alimento: podem ser carnívoros ou herbívoros. } \\
\text { Mamíferos se alimentam de leite materno e } \\
\text { depois de carnes e vegetais. } \\
\text { Mamíferos são carnívoros. dois grupos } \\
\text { escreveram ser Mamíferos são onívoros. São } \\
\text { carnívoros e herbivoros. } \\
\text { Respiram pelos pulmões e narinas. Respiram } \\
\text { pelo nariz. } \\
\text { Respiram pelos pulmões e brânquias. } \\
\text { Reprodução sexuada. } \\
\text { Reprodução assexuada. }\end{array}$ \\
\hline Aves & $\begin{array}{l}\text { Reprodução por ovos e assexuada. } \\
\text { Alimentação diversa. } \\
\text { Respiração pela narina e pulmão. }\end{array}$ \\
\hline
\end{tabular}

Quadro 3: Algumas respostas dadas pelos alunos.

Com relação aos peixes a característica que apresentou um maior número que anotações não aceitáveis foi a reprodução. Alguns alunos colocaram que peixes se reproduzem assexuadamente, assexuada externa ou assexuada com poucos gametas.

Pelas respostas dos alunos podemos inferir que não há clareza quanto aos conceitos de reprodução sexuada e assexuada e fecundação interna e externa. Possivelmente os alunos não associaram a reprodução sexuada ao encontro de gametas, o que fica ainda mais evidente na última resposta destacada. Reconhecemos que a reprodução dos peixes possui características peculiares (sexuada com fecundação interna ou externa, dependendo da espécie), o que nem sempre é lembrado por alunos do sétimo ano. Porém, entendemos que a não compreensão do conceito de "reprodução sexuada" é preocupante.

A mesma confusão quanto à reprodução pode ser constatada nos anfíbios, mas neste grupo a respiração também apresentou anotações equivocadas, como visto no quadro 03. Os anfíbios realmente apresentam diferentes tipos de respiração ao longo da vida, respiração branquial na fase larval e respiração pulmonar e cutânea na fase adulta. Esse fato pode ter contribuído para as incoerências nas respostas. Situação semelhante foi observada nas anotações sobre répteis (algumas apresentadas no quadro 03).

Novamente evidenciamos problemas no entendimento do processo de respiração e reprodução. Chama a atenção a confusão entre respiração cutânea, branquial e pulmonar e a não associação entre a respiração pulmonar e as narinas - alguns alunos parecem entender que há a respiração pulmonar e outro tipo relacionado às narinas. Novamente há citação a reprodução assexuada - o que confirma a existência de problemas na aquisição desse conceito. Além disso, evidenciamos que os alunos confundem répteis e anfíbios.

Quanto aos mamíferos, os resultados foram surpreendentes. De um total de dezesseis grupos, apenas dois citaram que os mamíferos se alimentam inicialmente de leite materno e depois passam a ter uma alimentação diversificada, como destacado no quadro 03. Os demais grupos registraram que os mamíferos têm alimentação diversificada: um grupo registrou que os mamíferos são carnívoros, dois grupos escreveram ser onívoros e onze grupos disseram que estes são carnívoros e herbívoros. Quanto à respiração, treze grupos registraram que os 
mamíferos realizam a respiração pulmonar, um grupo registrou "pulmões e narinas", outro grupo respondeu "pelo nariz" e um último resultado indicou "pulmões e brânquias". Já as características reprodutivas dos mamíferos foram descritas como sexuada por quinze grupos e assexuada por apenas um grupo. Mesmo pertencendo à classe dos mamíferos, os alunos não conseguiram descrever características alimentares, respiratórias e reprodutivas com exatidão. Esse fato pode nos indicar uma falta de correlação entre os conhecimentos apresentados e estudados na escola e a realidade do aluno. Nas respostas, percebemos a tentativa de correlação com o cotidiano, como destacado: "Respiração do mamífero: a respiração do cachorro é pelo pulmão."Nessa resposta há uma identificação dos cachorros como mamíferos e a correta citação de que esses realizam respiração pulmonar, porém nenhuma outra resposta citou exemplos de mamíferos, em nenhum momento há uma correlação com os humanos, o que pode transparecer que os alunos não se percebem como pertencentes a uma classificação ou não atrelam os conhecimentos estudados na escola ao seu cotidiano.

Novamente percebemos que há problemas na compreensão de conceitos relativos ao processo respiratório: há confusões entre respiração pulmonar e o entendimento da narina como sendo parte desse sistema; também parece haver falta de clareza sobre o que são brânquias. Quanto ao processo reprodutivo, realmente alguns alunos não compreenderam os conceitos de reprodução sexuada e assexuada, como confirmado ao citarem a reprodução das aves como assexuada.

Com essa primeira atividade de sondagem de conhecimentos dos alunos percebemos que há muitas lacunas em seu processo formativo que pode estar associada a um conhecimento escolar dissociado do cotidiano do aluno.

Conceitos importantes, que independem dos grupos que estamos trabalhando, aparentemente não estão claros para os alunos como reprodução e respiração. Falhas como essas podem comprometer o aprendizado de outros conteúdos relacionados.

Após essa sondagem inicial, os alunos tiveram a oportunidade de manusear exemplares conservados em álcool $70 \%$ de cada classe estudada (conforme já citado no quadro 1).
Durante essa etapa os grupos foram instigados a manusear e observar os exemplares e tentar relacionar com as características alimentares, respiratórias e reprodutivas já estudadas anteriormente na escola. A conversação com cada grupo foi guiada tendo como foco o processo evolutivo e como esse processo se faz perceptível nos exemplares manuseados.

Com a atividade de observação, manuseio e conversação a partir de um eixo evolutivo acreditamos que o conhecimento se torna mais significativo e compreensivo para o aluno, que passa a se ver como componente presente nesse processo.

Ao longo da atividade cada característica foi debatida com os grupos tendo como foco a modificação de tais características no processo evolutivo das espécies. Após o manuseio dos exemplares de animais, cada grupo apresentou uma classe para a turma, sintetizando as características abordadas (alimentação, respiração e reprodução). Como inicialmente trabalhamos com a formação de quatro grupos e, considerando as cinco classes presentes na atividade, optamos por agrupar peixes e anfíbios em um mesmo grupo de alunos. Esta opção se deve principalmente a presença de um único exemplar da classe dos peixes.

Durante a apresentação das classes pelos grupos de alunos, incentivamos a participação de todos. As características trabalhadas ao longo da atividade (alimentação, respiração e reprodução) foram exploradas pelos professores e monitores, que insistiam em indagar aos alunos como esses conseguiam perceber, nos exemplares, aspectos ligados às características. Ao fim das falas dos alunos foi possível perceber que esses passaram a expressar de forma cientificamente aceitável os aspectos explorados na atividade.

Em uma das turmas, o professor supervisor comentou que estava impressionado com a participação de alguns alunos que, em sala de aula regular, costumam apresentarem-se apáticos, mas durante a atividade tiveram uma ativa participação. Ao longo de toda atividade destacamos que os alunos apresentaram grande interesse em participar. Manusear alguns exemplares foi o ápice da atividade.

Ao final da atividade os grupos foram desafiados a tentar traçar um eixo evolutivo dos grupos estudados de acordo com suas 
características e os resultados nos surpreenderam:

\begin{tabular}{|c|c|c|}
\hline Ordem sugerida pelos grupos & Escola A & Escola B \\
\hline $\begin{array}{c}\text { Peixes, anfíbios, répteis, } \\
\text { mamíferos e aves }\end{array}$ & 4 & 5 \\
\hline $\begin{array}{c}\text { Peixes, anfíbios, répteis, aves } \\
\text { e mamíferos }\end{array}$ & 1 & 0 \\
\hline $\begin{array}{c}\text { Peixes, répteis, anfíbios, } \\
\text { mamíferos e aves }\end{array}$ & 3 & 2 \\
\hline $\begin{array}{c}\text { Peixes, répteis, mamíferos, } \\
\text { anfíbios, e aves }\end{array}$ & 0 & 1 \\
\hline
\end{tabular}

Quadro 4: Ordem evolutiva sugerida pelos grupos após a atividade experimental.

Como observável no quadro anterior, mais da metade dos grupos conseguiu estabelecer uma hipótese aceitável sobre a ordem evolutiva das espécies - embora atualmente se acredite que a partir dos dinossauros surgiram as aves e os répteis. Tal resultado expressa o quanto a atividade foi válida para a aquisição de conhecimentos que inclusive extrapolam o esperado para sétimo ano do Ensino Fundamental, já que a questão evolutiva não costuma ser muito trabalhada nesta esfera educativa.

\section{Considerações Finais}

A atividade realizada conseguiu despertar o interesse dos alunos, o que foi muito evidente devido à intensa participação. Atrelamos este fato à oportunidade de manusear exemplares de animais - o que costuma ser atrativo aos estudantes e pode propiciar importantes momentos de aprendizagem (GIORDAN, 1999; LOBO, 2012). Porém, apenas a atividade experimental não é uma garantia de sucesso no processo de ensino e aprendizado, como já indicado por Krasilchik (2004) e Hodson (1994). A abordagem do conteúdo de forma investigativa, conforme pontua Hodson (1994) e Silva, Machado e Tunes (2010), favorece a aprendizagem por instigar os indivíduos a buscar estratégias reflexivas que os auxiliem a avançar conceitualmente. A intensa participação dos alunos chamou a atenção dos professores que os acompanhavam e que atuam como
Supervisores no subprojeto Pibid de Ciências Naturais. Assim, acreditamos que esta atividade foi importante não só para o processo de ensino aprendizado de nossos alunos, como também para a reflexão e crescimento de todo o grupo Pibid (Coordenadores, Supervisores e Bolsistas de Iniciação à Docência).

Ao mesmo tempo, ao pensar na atividade experimental realizada não há como não citarmos Vygotsky e sua imensa contribuição aos processos de desenvolvimento humano. A atividade proporcionou a todo o grupo (alunos do $7^{\mathbf{o}}$ ano do Ensino Fundamental, alunos da Licenciatura em Ciências Naturais, professores da Educação Básica e da Universidade) preciosos momentos de interação e aproximação. Para Vygostky (1996), as funções psíquicas (como o processo de ensino e aprendizado) são de origem sociocultural, pois resultaram principalmente da interação do indivíduo com seu contexto cultural e social.Assim, ao considerar que a atividade experimental realizada proporcionou significativos momentos de interação entre o grupo e possibilitou o contato com conceitos cientificamente mais elaborados, afirmamos que esta atividade foi importante para o aprendizado de conceitos pelos participantes.

Ao propor uma atividade que enfoque principalmente os animais do cerrado, favorecemos $\mathrm{o}$ conhecimento desse tão importante bioma, frequentemente "tratado de modo descritivo, com reduzida análise da diversidade biológica e cultural do bioma e dos impactos negativos causados por determinadas ações antrópicas" (BIZERRIL \& FARIA, 2003). É fato que o bioma cerrado é tratado de forma reducionista nos livros didáticos (BIZERRIL, 2003), o que muitas vezes não só influencia a forma de abordagem do professor da Educação Básica, como reflete no contexto social - fato que nos ajuda a entender o porque desse bioma brasileiro ser atualmente o mais ameaçado de destruição (BIZERRIL \& FARIA, 2003). A atividade proporcionou aos alunos a experiência de estudar sobre as classes de animais que verdadeiramente compõe a fauna presente em seu cotidiano e a se percebam como indivíduos participantes desse complexo e importante meio, além de contribuir para uma visão do bioma cerrado mais compatível.

Acreditamos que atividades como essa favoreçam a aprendizagem de conceitos 
científicos e minimizem a observada confusão inicial identificada principalmente quanto a aspectos relacionados às características respiratórias e reprodutivas. Ao manusear os exemplares dos animais foi possível debater e elucidar, por exemplo, aspectos da respiração pulmonar, seus órgãos e funções. Após a atividade evidenciamos que os alunos já não utilizavam termos como "respiração pulmonar e pelas narinas", as narinas passaram a ser entendidas como um órgão que compõe esse sistema respiratório.

O mesmo pode ser identificado com relação ao conceito de reprodução sexuada e assexuada. Inicialmente evidenciamos que os alunos não atrelavam a reprodução sexuada ao encontro de gametas, mas ao contato físico e ao ato sexual. A atividade nos proporcionou momentos de discussão que possibilitaram o avanço no entendimento do conceito de reprodução sexuada como encontro de gametas.

Além dos conceitos pertinentes a característica respiratória, reprodutiva e alimentar, foi possível inserir o conceito de evolução das espécies. O conceito de evolução é hoje o pilar unificador da biologia moderna. Tal conceito é rotineiramente mal compreendido pelos alunos, que muitas vezes só se deparam com a concepção evolutiva no último ano do Ensino Médio. Acreditamos que o fato de introduzirmos essa conceituação nos anos finais do Ensino Fundamental favorece uma melhor compreensão dos aspectos evolutivos e da compreensão da Ciência como uma construção humana.

Atividades como a aqui descrita favorece tanto a aprendizagem dos alunos do Ensino Fundamental quanto à formação inicial e continuada de professores, motivo que nos leva a afirmar que o Programa Institucional de Bolsas de Iniciação à Docência - Pibid - é atualmente uma importante política pública em prol da melhoria educacional brasileira.

\section{Agradecimentos}

Os autores agradecem o apoio e a participação dos Professores Supervisores (SEDF), Licenciandos-Bolsistas (UnB) e alunos que participaram da atividade (SEDF).

\section{Referências}

BIZERRIL, M. X. A. . O cerrado nos livros didáticos de geografia e ciências. Ciência Hoje, Rio de Janeiro, v. 32, n.192, p. 56-60, 2003.

BIZERRIL, M. X. A. ; FARIA, D.S. . A escola e a conservação do Cerrado: uma análise no ensino fundamental do Distrito Federal. Revista Eletrônica do Mestrado em Educação Ambiental, Rio Grande - RS, v. 10, p. 19-31, 2003.

BRASIL. Senado Federal. Lei de diretrizes e bases da educação nacional: nº 4024/61.Brasília: 1961.

BRASIL. Senado Federal. Lei de diretrizes e bases da educação nacional: no 9394/96.Brasília: 1996.

BRASIL. Ministério da Educação, Secretaria da Educação Média e Tecnológica. Parâmetros Curriculares Nacionais. Brasília: MEC, 1999.

Ministério da Educação e dos Desportos. Secretaria de Educação Média e Tecnológica. Orientações educacionais complementares aos Parâmetros Curriculares Nacionais( $\mathrm{PCN}+$ ): Ciências da Natureza, Matemática e suas Tecnologias. Ensino Médio. Brasília: MEC, 2002.

BRASIL. Ministério da Educação, Secretaria de Educação Básica. Orientações Curriculares para o ensino médio; Linguagens, códigos e suas tecnologias. Brasília, 2006.

BRASIL. Ministério da Educação, Secretaria de Educação Básica. Diretrizes Curriculares Nacionais para a Educação Básica. Brasília, 2013.

CARVALHO, A.M.P. et al. Termodinâmica: um ensino por investigação. São Paulo: FEUSP; CAPES, 1999.

FRAGAL, V. H. ; MAEDA, S. M. ; PALMA, E. P. ; RODRIGUES, M. A.; BUZATTO, M. B. P. ; SILVA, E. L. . Uma proposta alternativa para o ensino de eletroquímica sobre a reatividade dos metais. Química Nova na Escola (Impresso), v. 33, p. 216-222, 2011.

Galiazzi, M. do C.; Gonçalves, F. P. A Natureza Pedagógica da Experimentação: Uma Pesquisa 
na Licenciatura em Química. Química Nova, 2004, Vol. 27, No. 2, 326-331.

GIORDAN, M. O papel da experimentação no ensino de ciências. Química Nova na Escola, São Paulo, SP 1999.

HODSON, D. Hacia un Enfoque más Crítico del Trabajo de Laboratorio. Enseñanza de las Ciencias, v. 12, n. 3, p. 299-313, 1994.

KRASILCHIK, M. Prática de Ensino de Biologia. 4. ed. São Paulo: EDUSP, 2004. v. 1. 197 p.

LÔBO, S. F. O trabalho experimental no ensino de Química. Química Nova, Vol 35, No. 2, 430434, 2012.

MAGALHÃES JÚNIOR, C. A.; PIETROCOLA, M. A formação dos professores de ciências para o Ensino Fundamental. In: Simpósio Nacional de Ensino De Física, 16, 2005, Rio de Janeiro. Ata.... Rio de Janeiro: Sociedade Brasileira de Física, 2005.

SILVA, R. R. ; MACHADO, P. F. L. ; TUNES, E. Experimentar sem medo de errar. In: SANTOS, W. L. P.; MALDANER, O. A. (Org.) Ensino de Química em foco. 1 ed. Ijuí: Editora Unijuí, 2010. p. 232-261.

SILVA, S. F.; NUNEZ, I. B. O ensino por problemas e trabalho experimental dos estudantes - Reflexões teórico-metodológicas. Química Nova, v. 25, n. 6b, p. 1197-1203, 2002.

SILVA, D. M. ; RAZUCK, R. C. S. R. . Aulas de campo para o Ensino Fundamental: contribuições para a percepção dos alunos sobre o meio ambiente. Revista da SBEnBIO, v. 5, p. 1, 2012.

SILVA, L. e ZANON, L.Ensino de Ciências: Fundamentos e Abordagens; organizado por Roseli P. Schnetzler e Rosália M. R. de Aragão. Campinas, SP, 2000.

VYGOTSKY, L.S. A formação social da mente: o desenvolvimento dos processos psicológicos superiores. 5.ed. São Paulo (Brasil): Martins Fontes, 1996. 